\title{
Cultura organizacional y satisfacción laboral como predictores del desempeño laboral en bibliotecarios
}

\author{
Shilia Lisset Vargas Echeverría* \\ Mirta Margarita Flores Galaz*
}

Artículo recibido:

7 de febrero de 2018

Artículo aceptado:

9 de enero de 2019

Artículo de investigación
Resumen

El presente artículo tuvo el objetivo de determinar si la cultura organizacional y la satisfacción laboral son predictores del desempeño laboral en bibliotecarios de la ciudad de Mérida, Yucatán, México. Participaron 193 bibliotecarios de diferentes bibliotecas universitarias y especializadas ubicadas en Mérida, 74 (38.30\%) fueron hombres y $114(59.10 \%)$ mujeres. Se administraron el Denison Organizational Culture Survey (Bonavia, Prado y Barberá, 2009), el Cuestionario de Satisfacción Laboral de Minnesota (Weiss et al., 1967) y la Escala de Desempeño Laboral para Bibliotecarios, propuesta en este trabajo. Los datos fueron procesados

* Universidad Autónoma de Yucatán, México

shilia.ve@gmail.com fgalaz@correo.uady.mx

INVESTIGACIÓN BIBLIOTECOLÓGICA, vol.33, núm. 79, abril/junio, 2019, México, ISSN: 2448-8321 pp. 149-176 
mediante el análisis de regresión múltiple (paso por paso) para la muestra global y por sexo. Los resultados mostraron que los factores de la cultura organizacional y la satisfacción laboral que predicen el desempeño son Responsabilidad/calidad; Actitud de servicio; Comunicación; Trabajo en equipo y Protección al medio ambiente.

Palabras clave: Cultura Organizacional; Satisfacción Laboral; Desempeño Laboral; Bibliotecarios; Medición

Organizational culture and labor satisfaction as predictors of job performance in librarians

Shilia Lisset Vargas Echeverría and Mirta Margarita Flores Galaz

\section{Abstract}

The objective of this article was to determine if organizational culture and labor satisfaction are predictors of job performance in librarians in Mérida city, Yucatán, México. 193 librarians participated coming from different university and specialized libraries located in Mérida, Yucatán. Of which 74 (38.30\%) were men and 114 (59.10\%) women. The Denison Organizational Culture Survey (Bonavia, Prado y Barberá, 2009), the Minnesota Job Satisfaction Questionnaire (Weiss et al., 1967) and the Escala de Desempeño Laboral para Bibliotecarios proposed in this article, were administered. The data were processed by multiple regression analysis (step by step) for the overall sample and by sex. The results showed that the factors of organizational culture and job satisfaction that predict performance are: Responsibility / quality, Service attitude, Communication, Teamwork and environmental protection.

Keywords: Organizational Culture; Job Satisfaction; Job Performance; Measurement 


\section{INTRODUCCIÓN}

— $\mathrm{n}$ la actualidad, se ha reconocido en las organizaciones que el medio Eambiente laboral incide y puede afectar el comportamiento de los trabajadores, predisponiéndolos de manera positiva o negativa; limitando o no la productividad, la creatividad y la identificación e implicación con las metas organizacionales. Es por eso que la cultura organizacional ha dejado de asumirse como una variable periférica para ser considerada como un activo intangible de fundamental importancia para las organizaciones. Su importancia ha sido un tema de gran interés desde la década de 1980 hasta nuestros días (Ouchi y Wilkins, 1985), desempeñando el papel de instrumento clave para lograr armonía y conciliación entre los intereses de todos sus miembros en torno a los propósitos que persigue.

El diagnóstico de cultura organizacional constituye una técnica avanzada de la administración y se ha convertido en el instrumento por excelencia para el cambio en busca del logro de una mayor efectividad organizacional, debido a que su objetivo fundamental consiste en detectar y evaluar las causas que afectan distintas variables en el desempeño del capital más importante con que cuenta cualquier organización: el capital humano (Chiavenato, 2011).

El estudio de la cultura organizacional se ha realizado, principalmente, en las organizaciones productivas (ya sean empresas u hospitales, entre otros). En los últimos años, estos estudios han comenzado a abrirse camino en las organizaciones educativas y, específicamente, en las bibliotecas (Hernández Pacheco, 2012; Lozano, 2009; Schlosser, 2010; Vargas, 2012; Zaragoza, 2012).

Todas las bibliotecas, sin importar su tamaño, poseen una cultura organizacional, misma que se va creando, construyendo y compartiendo entre todas las personas que se encuentran en su interior. Para que una biblioteca conozca sus potencialidades, ya sea mejorar la calidad de sus servicios o adaptarse a los constantes cambios del entorno, deberá estudiar y comprender su propia cultura (Vargas, 2012). En esta investigación la cultura organizacional es entendida como el conjunto de valores, creencias y principios fundamentales que constituyen los cimientos del sistema de una organización, así como también el conjunto de procedimientos y conductas que sirven de ejemplo y refuerzan esos principios básicos (Denison, 1991).

Uno de los aspectos que ha recibido mayor atención en el estudio de la cultura organizacional es la satisfacción laboral como un recurso indispensable para que las organizaciones obtengan resultados positivos en cuanto al recurso humano, pues su trabajo es fundamental para el logro de los objetivos organizacionales y, por tanto, para el fomento de una cultura organizacional satisfactoria (Lok y Crawford, 1999; Lund, 2003; Silverthorne, 2004). 
Además, la satisfacción de los trabajadores ocupa un lugar preferente, ya que su percepción negativa o positiva influye en la relación que adopten con la organización y el nivel de compromiso que tengan con ella (Hinojosa, 2010).

La satisfacción laboral puede ser entendida como el estado emocional, sentimientos o respuestas afectivas que reflejan una actitud generalizada ante el trabajo o ante la situación laboral. Estas actitudes pueden ir referidas hacia el trabajo en general o hacia facetas específicas (Bravo, Peiró y Rodríguez, 1996; Griffin y Bateman, 1986; Ivancevich, Konopaske y Matteson, 2006; Robbins y Judge, 2013).

A partir de lo anterior, conocer la cultura organizacional y el grado de satisfacción laboral de los trabajadores es primordial, ya que esto permitirá a los directivos de la biblioteca tomar las medidas necesarias para contar con un talento humano efectivo, proactivo y satisfecho con el trabajo desempeñado y, de esta manera, alcanzar la efectividad organizacional.

Un segundo aspecto relacionado estrechamente con la cultura organizacional y la satisfacción laboral es el desempeño laboral, ya que en la medida en que los trabajadores perciban mayores niveles de satisfacción o insatisfacción, su nivel de desempeño laboral redundará, de manera visible, en una mayor o menor productividad (Peña, Olloqui y Aguilar, 2013). En vista de lo anterior, el desempeño laboral puede concebirse como aquellas acciones, comportamientos y resultados escalables en los que los empleados se involucran, están vinculados y contribuyen al logro de las metas de la organización (Viswesvaran y Ones, 2000).

Además, alinear hacia un mismo objetivo los tres aspectos anteriores permitirá, de manera interna, elevar la eficiencia y efectividad de las bibliotecas, vinculando los intereses de los miembros de la organización con las metas institucionales, de manera que éstas se cumplan y se proporcione un valor agregado a los productos y servicios ofrecidos (Quijano, 2007).

$\mathrm{Al}$ interior de las bibliotecas se encuentran los bibliotecarios, unos profesionales de la información que se encargan de contribuir y apoyar a la formación y desarrollo de la comunidad de usuarios que atiende la biblioteca, complementando y reforzando la labor de la escuela o universidad en la cual se encuentra inserta y, por consiguiente, contribuyendo al alcance de los objetivos institucionales. Por esta razón resulta relevante que las variables cultura organizacional, satisfacción laboral y desempeño laboral se analicen dentro del contexto de las bibliotecas mexicanas.

Tratando de aproximarse al estudio de este fenómeno en la realidad, la presente investigación propone estudiar la organización denominada biblioteca y al capital humano que labora en ella: los bibliotecarios y, sobre todo, conocer cómo éstos responden a las necesidades actuales desde dos posturas 
diferentes: la organización y los individuos. Desde la primera se estudiará la cultura organizacional como una respuesta de la organización a los cambios actuales. Desde la segunda se analizará la satisfacción laboral y el desempeño laboral para conocer cómo viven los cambios las personas internas de la biblioteca y a través de ello conocer si está cumpliendo su función en la sociedad.

Aunado a ello, cabe mencionar que en la literatura relacionada son escasos los estudios sobre las variables cultura organizacional, satisfacción laboral y desempeño organizacional de forma simultánea en una misma investigación, es decir, las investigaciones que se han realizado en este sentido han abordado los conceptos de forma aislada. A pesar de existir algunas investigaciones que vinculan la cultura organizacional con la satisfacción laboral (Flynn y Chatman, 2001; Kusluvan y Karamustafa, 2003; Lok y Crawford, 1999; Lund, 2003; Lukić et al., 2014; Silverthorne, 2004), la cultura organizacional con el desempeño laboral (Martínez, 2010) o la satisfacción laboral con el desempeño laboral (Hobson, Moran y Stevens, 1987; Lewis, 1980; Oyewole y Popoola, 2013; Peng, 2014), no se encontró ninguna que integre las tres variables, por lo que se puede afirmar que no existen estudios en $\mathrm{Yu}$ catán que incluyan las tres variables para dar una explicación conjunta. Sobre todo, para conocer cómo se comportan estas variables en una organización muy particular, como es la biblioteca.

En este contexto, la presente investigación pretende analizar la relación existente entre las variables antes mencionadas, es decir, la relación entre la cultura organizacional y la satisfacción laboral, incluyendo algunas variables sociodemográficas que podrían influir, y su efecto en el desempeño laboral de los bibliotecarios. Por lo tanto, el objetivo de esta investigación fue determinar si la cultura organizacional y la satisfacción laboral son predictores del desempeño laboral en bibliotecarios.

\section{Metodología}

\section{Participantes}

Participó todo el personal bibliotecario de la ciudad de Mérida que estaba laborando en bibliotecas universitarias y especializadas durante el periodo enero-julio de 2017. Las bibliotecas estudiadas fueron 38 universitarias y 15 especializadas, con 135 y 58 bibliotecarios respectivamente, sumando un total de 193 bibliotecarios, de los cuales 74 (38.30\%) fueron hombres y 114 $(59.10 \%)$ mujeres, nueve no respondieron. La mayoría de los bibliotecarios 
tenían licenciatura, con $45.10 \%$ (87); en segundo lugar, $32.1 \%$ (62) de los bibliotecarios tenían estudios de posgrado; en tercer lugar, $18.7 \%$ (36) tenían preparatoria y el resto, $4.1 \%$ (8), secundaria. La mayor parte de la población, es decir, $61.5 \%$ (115) se dedica a realizar funciones de servicios al público, $27.1 \%$ (52) realiza funciones de procesos técnicos y $11.4 \%$ (21) se dedica a la administración general de la biblioteca. Estas son las labores básicas que debe realizar el personal de una biblioteca según la teoría, lo que claramente se puede ver reflejado en el estudio.

\section{Instrumentos}

Se les administraron tres instrumentos: el Denison Organizational Culture Survey (DOCS), el Cuestionario de Satisfacción Laboral de Minnesota y la Escala de Desempeño Laboral para Bibliotecarios. El primero es un instrumento de origen anglosajón, creado por Denison (1991), autor clásico en los estudios sobre cultura organizacional. Su modelo es el resultado de más de 50 años de investigación para demostrar el impacto que tiene la cultura organizacional y los procedimientos administrativos sobre el rendimiento, el desempeño y la efectividad organizacional. El instrumento ha sido traducido y validado al castellano por Bonavia, Prado y Barberá (2009) y ha sido aplicado a una gran cantidad de organizaciones (más de 700 según sus autores) de diferentes países. Esta escala, en su versión castellana, contempla 60 reactivos en un formato tipo Likert de cinco opciones de respuesta (Apéndice $A$ ) y se compone, de acuerdo con el modelo de Denison, de cuatro dimensiones principales, las cuales se describen con sus respectivas consistencias internas obtenidas para la muestra yucateca:

- Involucramiento, se refiere a la capacidad de los miembros de la biblioteca de organizarse en equipos y desarrollarse profesionalmente, así como participar activamente en las decisiones (alfa $=.91$ );

- Consistencia, se refiere a la capacidad de tener valores comunes compartidos entre todos los miembros que faciliten el alcance de acuerdos $($ alfa $=.87)$;

- Adaptabilidad, esta dimensión toma en cuenta el entorno externo donde los bibliotecarios interactúan con sus usuarios, asumen riesgos, aprenden de sus errores y continuamente introducen cambios ( $\mathrm{alfa}=$ $.83), \mathrm{y}$

- Misión, se refiere a la existencia de una dirección y un propósito definido, así como una clara visión del futuro de la biblioteca $(a l f a=.95)$ (Bonavia, Prado y Barberá, 2009). 
A su vez, las dimensiones anteriores se agrupan en 12 subdimensiones, tres subescalas para cada dimensión: Empoderamiento, Orientación al equipo y Desarrollo de capacidades dentro de la dimensión Involucramiento; Valores centrales, Acuerdo y Coordinación e integración se agrupan dentro de la Consistencia; Creación del cambio, Enfoque al cliente y Aprendizaje organizacional pertenecen a la dimensión Adaptabilidad, y Dirección e integración estratégica, Metas y objetivos y Visión se incluyen dentro de la Misión. Seguidamente, se describen las subdimensiones mencionadas con las consistencias internas correspondientes para cada una: Empoderamiento, donde los bibliotecarios tienen autoridad, iniciativa y capacidad para dirigir su propio trabajo $($ alfa $=.80)$; Orientación al equipo, se refiere al trabajo cooperativo hacia objetivos comunes $(\mathrm{alfa}=.82)$; Desarrollo de capacidades, se refiere a la inversión de recursos en el desarrollo y mejora profesional de los bibliotecarios para aprovechar nuevas oportunidades (alfa $=.83$ ); Valores centrales, los bibliotecarios comparten valores que dan lugar a expectativas claras y un sentimiento de identidad ( $\mathrm{alf} a=.70)$; Acuerdo, se refiere a la capacidad de llegar a acuerdos en temas esenciales para poder solventar las diferencias $($ alfa $=.71)$; Coordinación e integración, los bibliotecarios de diferentes niveles jerárquicos son capaces de trabajar de forma conjunta con el fin alcanzar objetivos comunes $($ alfa $=.75)$; Creación del cambio, hace alusión a que la biblioteca es capaz de buscar, detectar, interpretar y anticipar cambios en su entorno para reaccionar a éstos adecuadamente (alfa $=.68)$; Enfoque al cliente, implica que la biblioteca esté guiada y preocupada constantemente por la satisfacción de las necesidades de sus usuarios $(a l f a=.69)$; Aprendizaje organizacional, se refiere a que la biblioteca recibe, analiza y utiliza las señales de su entorno con el fin de favorecer la innovación, desarrollo y conocimiento $($ alfa $=.59)$; Dirección e integración estratégica, se refiere a la importancia de disponer de un plan estratégico claro que determine el propósito de la biblioteca, mostrando a todos sus miembros cómo pueden contribuir al desarrollo de la misma (alfa $=.86)$; Metas y objetivos, deben estar vinculados a la misión y visión de la biblioteca para que los bibliotecarios conozcan la dirección que debe seguir su trabajo (alfa = 90); y Visión, donde la organización tiene una imagen compartida de sí misma que refleja el modo en cómo debe ser percibida en el futuro (alfa = .82) (Bonavia, Prado y Barberá, 2009).

El Cuestionario de Satisfacción Laboral de Minnesota (MSQ, del inglés Minnesota Satisfaction Questionnaire) (Weiss et al., 1967) está diseñado para medir la satisfacción de un empleado con su trabajo. El MSQ proporciona información específica sobre los aspectos del trabajo que un individuo encuentra gratificantes. El cuestionario es un instrumento reconocido internacionalmente 
con gran vigencia en la actualidad, que ha sido traducido al chino, francés, griego, coreano, portugués, sueco, español, polaco, taiwanés, entre otros idiomas. Esta escala, en su versión anglosajona, ha presentado una adecuada consistencia interna (que va de .97 en la dimensión más alta a .59 en la dimensión más baja), validez del constructo y estructura factorial (Weiss et al., 1967). En este estudio se trabajó con una versión corta del MSQ conformada por las siguientes 13 dimensiones (Apéndice B), para las cuales se presenta también la consistencia interna obtenida en la muestra yucateca: Compañeros de trabajo, se refiere a la forma en que los bibliotecarios se llevan entre sí (alfa $=.89$ ); Responsabilidad, se refiere a la libertad de cada persona para utilizar su propio juicio (alfa $=.83$ ); Seguridad, es la forma en que el trabajo les proporciona estabilidad ( $\mathrm{alfa}=.87$ ); Reconocimiento, es el elogio que reciben por hacer un buen trabajo $(\mathrm{alf} a=.92)$; Supervisión-relaciones humanas, se refiere a la forma en que el jefe se encarga de sus empleados (alfa $=.91$ ); Oportunidades de promoción, hace alusión a las oportunidades de los bibliotecarios de desarrollarse profesionalmente $(\mathrm{alfa}=.94)$; Condiciones de trabajo, se refiere a los aspectos físicos y ambientales del lugar de trabajo (alfa $=.90)$; Políticas de la compañía y prácticas, es la forma en que las políticas de la biblioteca se ponen en práctica (alfa $=.89)$; Estatus social, se refiere a la oportunidad de los bibliotecarios de ser alguien en la comunidad ( $\mathrm{alfa}=.87$ ); Logro, es el sentimiento de logro que obtienen del trabajo que realizan ( $a l f a=.83)$; Servicio social, son las oportunidades de hacer cosas por otras personas $(\mathrm{alfa}=.88)$; Variedad, se refiere a las oportunidades de hacer cosas diferentes de vez en cuando (alfa= .80), y Compensación, es el pago que reciben los bibliotecarios en relación con la cantidad de trabajo que realizan ( $\mathrm{alfa}=.93)$; sumando un total de 65 reactivos, cinco por cada dimensión, también en un formato tipo Likert (Weiss et al., 1967).

La Escala de Desempeño Laboral para Bibliotecarios se desarrolló a partir de la revisión de tres perfiles de puestos de tres bibliotecas ubicadas en la ciudad de Mérida, por ser bibliotecas grandes que tienen perfectamente identificadas las categorías del personal y, también, ampliamente desarrolladas sus funciones. De esta forma, se revisó cada una de las competencias que conforman los diferentes perfiles, comparándolos e integrándolos entre sí. El resultado fue la integración de un perfil genérico que pueda ser aplicable para todas las bibliotecas estudiadas y a partir del cual se definieron las competencias seleccionadas y se desarrollaron los reactivos para cada una de ellas. Así, se creó la Escala de Desempeño Laboral para Bibliotecarios, la cual consta de cinco factores que explican el $64.65 \%$ de la varianza total. Las dimensiones que la conforman se describen con sus respectivas consistencias internas: Responsabilidad/calidad, describe la capacidad de poder cumplir en tiempo y forma con las funciones y 
actividades acordadas para desempeñar el trabajo a la perfección (alfa $=.95$ ); Actitud de servicio, implica mostrar disposición para servir en las actividades diarias de manera amable, atenta y con rapidez, logrando satisfacer las necesidades de los usuarios (alfa $=.92)$; Comunicación, es transmitir información de manera que la otra persona la entienda con el mensaje correcto, así como también entender adecuadamente la información se que recibe de vuelta (al$\mathrm{fa}=.90$ ); Trabajo en equipo, involucra participar activamente para lograr los objetivos y metas del equipo de trabajo (alfa $=.88)$, y Protección al medio ambiente, se refiere a proteger los recursos naturales o sus derivados al realizar las tareas del trabajo, reduciendo, reutilizando y reciclando dichos recursos (alfa= .81). La escala quedó conformada por 31 reactivos presentados en escala tipo Likert con cinco opciones de respuesta (Apéndice C).

\section{Procedimiento}

Debido a que el número de bibliotecas universitarias y especializas ubicadas en la ciudad de Mérida es reducido, la muestra fue tipo censo. El trabajo de campo consistió en visitas a cada una de las bibliotecas y en la aplicación de los tres instrumentos, de forma simultánea. El proceso de respuesta tuvo como duración unos 40 minutos aproximadamente.

\section{Análisis de datos}

Para el análisis de los datos se utilizó el programa estadístico Statistical Package for the Social Sciences (SPSS) en su versión 24. En primer lugar, se realizó un análisis descriptivo a través de medias y desviaciones estándar, así como también se obtuvo un análisis de consistencia interna para determinar la confiabilidad de cada uno de los factores de las escalas utilizadas por medio del Coeficiente Alfa de Cronbach (1951). En segundo lugar, se llevó a cabo un análisis de regresión múltiple que tuvo como objetivo determinar cuáles de los factores de la cultura organizacional y de la satisfacción laboral predicen el desempeño laboral de los bibliotecarios.

\section{Resultados}

\section{Análisis descriptivo}

Para el primer instrumento, el Cuestionario Denison Organizational Culture Survey, la media global de la escala fue de 3.63, con una desviación estándar 
de .86. Asimismo se encontró la media más alta en el factor Dirección e integración estratégica $(M=3.86)$ y la media más baja se encontró en el factor Creación del cambio $(M=3.49)$. Todas las medias estuvieron por arriba de la media teórica. La consistencia interna global de la escala fue alta con un alfa de .96 (Tabla 1). Cabe destacar que se eliminaron cuatro reactivos del instrumento original, considerados débiles ya que mostraban una correlación ítem inferior a 20 .

\begin{tabular}{|c|c|c|c|c|c|}
\hline Factor & Subfactor & $\alpha$ & $M$ & $\mathrm{DE}$ & Reactivos \\
\hline \multirow[t]{3}{*}{ Involucramiento } & 1. Empoderamiento & .80 & 3.83 & .74 & 5 \\
\hline & 2. Orientación al equipo & .82 & 3.80 & .78 & 5 \\
\hline & 3. Desarrollo de capacidades & .83 & 3.50 & .87 & 4 \\
\hline \multirow[t]{3}{*}{ Consistencia } & 4. Valores centrales & .70 & 3.56 & .72 & 5 \\
\hline & 5. Acuerdo & .71 & 3.56 & .83 & 4 \\
\hline & 6. Coordinación e integración & .75 & 3.53 & .76 & 5 \\
\hline \multirow[t]{3}{*}{ Adaptabilidad } & 7. Creación del cambio & .68 & 3.49 & .65 & 4 \\
\hline & 8. Enfoque al cliente & .69 & 3.83 & .62 & 4 \\
\hline & 9. Aprendizaje organizacional & .59 & 3.68 & .60 & 4 \\
\hline \multirow[t]{3}{*}{ Misión } & 10. Dirección e integración estratégica & .86 & 3.86 & .84 & 4 \\
\hline & 11. Metas y objetivos & .90 & 3.61 & .91 & 5 \\
\hline & 12. Visión & .82 & 3.68 & .82 & 4 \\
\hline
\end{tabular}

Tabla 1. Alfas, medias y desviaciones estándar de los subfactores de la cultura organizacional

Para el caso del Cuestionario de Satisfacción Laboral de Minnesota, nuevamente todos los factores se encuentran por arriba de la media teórica, con excepción de Compensación $(\mathrm{M}=2.91)$. Se puede observar que la media más alta se obtuvo en el factor Servicio social $(\mathrm{M}=4.14)$. La media global fue de 3.52 con una desviación estándar de .90 y la consistencia interna de toda la escala obtuvo un alfa de .98 (Tabla 2).

\begin{tabular}{|l|c|c|c|c|}
\hline \multicolumn{1}{|c|}{ Factor } & $\boldsymbol{\alpha}$ & $\boldsymbol{M}$ & $\mathrm{DE}$ & Reactivos \\
\hline 1. Compañeros de trabajo & .89 & 3.43 & .89 & 5 \\
\hline 2. Responsabilidad & .83 & 3.68 & .75 & 5 \\
\hline 3. Seguridad & .87 & 3.60 & .91 & 5 \\
\hline 4. Reconocimiento & .92 & 3.37 & .98 & 5 \\
\hline 5. Supervisión-relaciones humanas & .91 & 3.38 & 1.01 & 5 \\
\hline 6. Oportunidades de promoción & .94 & 3.04 & 1.12 & 5 \\
\hline 7. Condiciones de trabajo & .90 & 3.55 & .95 & 5 \\
\hline
\end{tabular}




\begin{tabular}{|l|c|c|c|c|}
\hline 8. Políticas de la compañía y prácticas & .89 & 3.31 & .94 & 5 \\
\hline 9. Estatus social & .87 & 3.64 & .80 & 5 \\
\hline 10. Logro & .83 & 3.83 & .74 & 5 \\
\hline 11. Servicio social & .88 & 4.14 & .68 & 5 \\
\hline 12. Variedad & .80 & 3.78 & .83 & 5 \\
\hline 13. Compensación & .93 & 2.91 & 1.09 & 5 \\
\hline
\end{tabular}

Tabla 2. Alfas, medias, desviaciones estándar y reactivos de los factores de la satisfacción laboral

Para la Escala de Desempeño Laboral para Bibliotecarios se aprecia que el factor Actitud de servicio tuvo la media más alta $(M=4.41)$ y el factor Comunicación obtuvo la media más baja $(\mathrm{M}=3.51)$. Asimismo la media global de la escala fue de 3.20 con una desviación estándar de .76. La consistencia interna total de la escala obtuvo un alfa de .95 (Tabla 3).

\begin{tabular}{|l|c|c|c|c|}
\hline \multicolumn{1}{|c|}{ Factor } & $\boldsymbol{\alpha}$ & $\boldsymbol{M}$ & DE & Reactivos \\
\hline 1. Responsabilidad/calidad & .95 & 4.29 & .58 & 14 \\
\hline 2. Actitud de servicio & .92 & 4.41 & .56 & 6 \\
\hline 3. Comunicación & .90 & 3.51 & .99 & 4 \\
\hline 4. Trabajo en equipo & .88 & 3.73 & .94 & 3 \\
\hline 5. Protección al medio ambiente & .81 & 4.16 & .73 & 4 \\
\hline
\end{tabular}

Tabla 3. Medias, desviaciones estándares, consistencia interna y número de reactivos por factor de la Escala de Desempeño Laboral para Bibliotecarios

\section{Análisis de regresión múltiple}

Para conocer cuáles de los factores de la cultura organizacional y de la satisfacción laboral predicen el desempeño laboral de los bibliotecarios se utilizó un análisis de regresión múltiple, con el método paso a paso. Es importante mencionar que dicho análisis se realizó considerando los subfactores de la cultura organizacional (Empoderamiento, Orientación al equipo, Desarrollo de capacidades, Valores centrales, Acuerdo, Coordinación e integración, Creación del cambio, Enfoque al cliente, Aprendizaje organizacional, Dirección e integración estratégica, Metas y objetivos, y Visión) y los factores de la satisfacción laboral (Compañeros de trabajo, Responsabilidad, Seguridad, Reconocimiento, Supervisión-relaciones humanas, Oportunidades de promoción, Condiciones de trabajo, Políticas de la compañía y prácticas, Estatus social, Logro, Servicio social, Variedad y Compensación), para la predicción del desempeño laboral, tanto para la muestra general como por sexo. 
El análisis de regresión múltiple para la muestra global mostró que se obtuvieron cinco modelos de predicción, en el primer paso se incluyó en la ecuación el factor Supervisión-relaciones humanas como predictor, el cual explicó $45.2 \%$ de la varianza, $F(1,170)=139.534, \mathrm{p}=<.001$. En el segundo paso, se incorporó en la ecuación el Logro como predictor, que explicó 54.2 \% de la varianza, $F_{\text {incrementada }}(2,170)=99.379, \mathrm{p}=<.001$. En el tercer paso se agregó el Acuerdo, el cual explicó $59.6 \%$ de la varianza, $F_{\text {incrementada }}(3,170)=82.081, \mathrm{p}$ $=<.001$. En el cuarto paso, se incorporó el Aprendizaje organizacional como predictor, que explicó $60.6 \%$ de la varianza, $F$ incrementada $(4,170)=63.792, \mathrm{p}=$ $<.001$. En el quinto paso, se añadió el factor Oportunidades de promoción, que explicó $61.5 \%$ de la varianza, $F$ incrementada $\left({ }_{5,170}\right)=52.709, \mathrm{p}=<.001$.

En la Tabla 4 se muestra el modelo final de regresión estimado, donde se demostró una correlación múltiple $\left(\mathrm{R}=.784 ; \mathrm{R}^{2}=.615\right)$, lo cual indica que $61.5 \%$ de la varianza del desempeño laboral global es explicado a partir de la Supervisión-relaciones humanas, el Logro, el Acuerdo, el Aprendizaje organizacional y las Oportunidades de promoción.

\begin{tabular}{|l|c|c|c|c|c|}
\hline \multicolumn{1}{|c|}{ Subfactores/Factores } & B & $\begin{array}{c}\text { Error } \\
\text { estándar }\end{array}$ & Beta & $\mathbf{t}$ & Sig. \\
\hline Supervisión-relaciones humanas & .213 & .041 & .385 & 5.223 & $.001^{\star \star \star}$ \\
\hline Logro & .255 & .050 & .339 & 5.095 & $.001^{\star \star \star}$ \\
\hline Acuerdo & .174 & .041 & .250 & 4.214 & $.001^{\star \star \star}$ \\
\hline Aprendizaje organizacional & .134 & .057 & .144 & 2.364 & $.019^{\star}$ \\
\hline Oportunidades de promoción & -.077 & .039 & -.154 & -1.977 & $.050^{\star}$ \\
\hline
\end{tabular}

${ }^{*} p \leq .05 ;{ }^{* \star} p \leq .01 ;{ }^{* \star *} p \leq .001 R=.784 ; R^{2}=.615 F(5,170)=52.71, p<.001$

Tabla 4. Análisis de regresión múltiple global obtenido para la predicción del factor desempeño laboral, a partir de los subfactores de la cultura organizacional y los factores de la satisfacción laboral

El análisis de regresión múltiple obtenido para la muestra de hombres mostró tres modelos de predicción, en el primer paso se añadió en la ecuación el factor Supervisión-relaciones humanas como predictor, el cual explicó $49.7 \%$ de la varianza, $F\left({ }_{1,65}\right)=63.315, \mathrm{p}=<.001$. En el segundo paso, se agregó en la ecuación el Estatus social como predictor, que explicó 61.9 \% de la varianza, $F$ incrementada $\left(2,{ }_{65}\right)=51.169, \mathrm{p}=<.001$. En el tercer paso, se adicionó el Acuerdo como predictor, que explicó el $67.8 \%$ de la varianza, $F$ incrementada $(3,65)=43.424, \mathrm{p}=<.001$.

En la Tabla 5 se muestra el modelo final de regresión estimado, donde se demostró una correlación múltiple $\left(\mathrm{R}=.823 ; \mathrm{R}^{2}=.678\right)$, lo cual indica que $67.8 \%$ de la varianza del desempeño laboral en hombres es explicado a partir de la Supervisión-relaciones humanas, el Estatus social y el Acuerdo. 


\begin{tabular}{|l|c|c|c|c|c|}
\hline \multicolumn{1}{|c|}{ Factores/Subfactores } & B & $\begin{array}{c}\text { Error } \\
\text { estándar }\end{array}$ & Beta & t & Sig. \\
\hline Supervisión-relaciones humanas & .201 & .039 & .436 & 5.094 & $.001^{\star * *}$ \\
\hline Estatus social & .214 & .063 & .300 & 3.385 & $.001^{\star \star *}$ \\
\hline Acuerdo & .183 & .055 & .284 & 3.356 & $.001^{\star \star *}$ \\
\hline
\end{tabular}

${ }^{*} p \leq .05 ;{ }^{* *} p \leq .01 ;{ }^{* * *} p \leq .001 R=.823 ; R^{2}=.678 F\left({ }_{3,65}\right)=43.424, p<.001$

Tabla 5. Análisis de regresión múltiple obtenido para la predicción del factor desempeño laboral, a partir de los subfactores de la cultura organizacional y los factores de la satisfacción laboral en hombres

Por otra parte, el análisis de regresión múltiple obtenido para las mujeres mostró que se encontraron cuatro modelos de predicción. En el primer paso se añadió en la ecuación el factor Supervisión-relaciones humanas como predictor, el cual explicó $48.2 \%$ de la varianza, $F\left({ }_{1,100}\right)=91.945$, p $=<$ .001. En el segundo paso, se incluyó el Acuerdo como predictor, que explicó $55.4 \%$ de la varianza, $F$ incrementada $(2,100)=60.786, \mathrm{p}=<.001$. En el tercer paso, se incorporó el Logro como predictor, el cual explicó 59.7 \% de la varianza, $F_{\text {incrementada }}\left({ }_{3,100}\right)=47.935, \mathrm{p}=<.001$. En el cuarto paso, se adicionó la Dirección e integración estratégica como predictor, que explicó $61.4 \%$ de la varianza, $F_{\text {incrementada }}\left({ }_{4,100}\right)=38.168, \mathrm{p}=<.001$.

En la Tabla 6 se muestra el modelo final de regresión estimado, donde se demostró una correlación múltiple $\left(\mathrm{R}=.784 ; \mathrm{R}^{2}=.614\right)$, lo cual indica que $61.4 \%$ de la varianza del desempeño laboral en mujeres es explicado a partir de la Supervisión-relaciones humanas, el Acuerdo, el Logro y la Dirección e integración estratégica.

\begin{tabular}{|l|c|c|c|c|c|}
\hline \multicolumn{1}{|c|}{ Factores/Subfactores } & B & $\begin{array}{c}\text { Error } \\
\text { estándar }\end{array}$ & Beta & t & Sig. \\
\hline Supervisión-relaciones humanas & .185 & .060 & .297 & 3.069 & $.011^{\star *}$ \\
\hline Acuerdo & .144 & .056 & .201 & 2.589 & $.000^{\star \star *}$ \\
\hline Logro & .125 & .072 & .286 & 2.965 & $.004^{\star \star}$ \\
\hline Dirección e integración estratégica & .118 & .058 & .166 & 2.042 & $.044^{\star \star}$ \\
\hline
\end{tabular}

${ }^{\star} p \leq .05 ;{ }^{* \star} p \leq .01 ;{ }^{* \star *} p \leq .001 R=.784 ; R^{2}=.614 F(4,100)=38.168, p<.001$

Tabla 6. Análisis de regresión múltiple obtenido para la predicción del factor desempeño laboral, a partir de los subfactores de la cultura organizacional y los factores de la satisfacción laboral en mujeres 


\section{Discusión}

Los datos arrojaron que los cuatro rasgos culturales identificados en el modelo de cultura organizacional de Denison (1991) estuvieron relacionados, de diferente manera, con criterios de efectividad en las bibliotecas estudiadas. De esta forma, se encontró que la Misión y el Involucramiento fueron los factores más representativos de la cultura organizacional de los bibliotecarios, inclinándose más hacia la estabilidad. Todas las dimensiones puntuaron por arriba de la media teórica. Sin embargo, el puntaje más alto se obtuvo en el factor Misión, seguido por el Involucramiento, la Adaptabilidad y la Consistencia. Un resultado similar fue el de Martínez (2010), quien utilizó también el modelo de Denison en una muestra de empresas colombianas y obtuvo casi el mismo resultado, únicamente invirtiendo la Adaptabilidad por la Consistencia. Estas diferencias podrían deberse al tipo de organización donde se aplicó, que en el caso anterior fueron 11 empresas con fines de lucro: nueve del sector manufacturero, una del sector de extracción y otra del sector financiero.

Con respecto a las subdimensiones, se encontró que el puntaje más alto lo obtuvo Dirección e integración estratégica, perteneciente a la dimensión Misión, lo cual corrobora la inclinación de los bibliotecarios por tener un sentido claro de misión y propósito en su biblioteca, así como la importancia de disponer de un plan estratégico que permita alcanzar dicha misión. Otra subdimensión con puntaje elevado fue el Enfoque al cliente, o en el caso de los bibliotecarios, al usuario. Esta subdimensión tuvo un puntaje elevado en las tres variables estudiadas, tal como se explicará más adelante.

Se encontró también que los mayores satisfactores laborales de los bibliotecarios yucatecos fueron el Servicio a los usuarios y el Logro. En esta investigación se corroboró que los bibliotecarios están satisfechos con el servicio que ofrecen a sus usuarios y a la comunidad en general (Seoko, 1978), como la oportunidad que tienen para servir a los demás, ayudarlos en sus necesidades informativas y otorgarles un pequeño servicio en retribución de lo que la organización hace por ellos.

Otras investigaciones sustentan la predicción de que el Logro de valores guarda relación positiva con la satisfacción en el trabajo (Ferris, Witt y Hochwarter, 2001) así como también con los valores individuales y organizacionales de las personas y con la cultura organizacional de la empresa (Diskienè y Goštautas, 2010). De esta forma, los administradores pueden mejorar la satisfacción de los empleados al mejorar el ambiente laboral, sus retribuciones y sus reconocimientos para reforzar sus valores. En este estudio, el Logro alcanzó un valor elevado como un factor de gran satisfacción en los bibliotecarios, 
similar al estudio realizado por Morgan (2014) aplicado a profesionales de la información, graduados de la Maestría Library and Information Science. La principal conclusión del estudio es que la Noción de artesanía y el Logro profesional son los mayores determinantes de la satisfacción en el trabajo.

Los factores que mejor describen el desempeño laboral de los bibliotecarios fueron la Actitud amable y atenta para dar servicio a sus usuarios y la Responsabilidad/calidad que les permite realizar de forma adecuada su trabajo. Una investigación que resalta la importancia de considerar los factores Servicio y Calidad al medir el desempeño laboral es la de Hobson, Moran y Stevens (1987), quienes encontraron que las habilidades interpersonales mejoran el desempeño laboral de los bibliotecarios, mejorando por consiguiente la calidad interpersonal de los servicios proporcionados y, por tanto, la satisfacción tanto de jefes como de usuarios. Siguiendo con este enfoque, los bibliotecarios manifestaron tener Responsabilidad/calidad y una buena Actitud de servicio al momento de interactuar y tratar con los usuarios, es decir, perciben cumplir en tiempo y forma con las funciones y actividades acordadas para desempeñar el trabajo de la forma más adecuada. También expresaron tener disposición para servir en las actividades diarias de manera amable y atenta logrando, desde su perspectiva, satisfacer las necesidades de los usuarios.

Los resultados obtenidos en el estudio reflejan que los bibliotecarios de las universidades y centros de investigación de la ciudad de Mérida muestran una percepción positiva de la cultura organizacional, de la satisfacción laboral y, por consiguiente, del desempeño laboral (Flynn y Chatman 2001; Kusluvan y Karamustafa, 2003). Un factor que corrobora esta afirmación, ya que obtuvo un puntaje alto en las tres variables estudiadas, fue el Servicio. Esto ratifica que brindar un servicio de calidad forma parte de la cultura organizacional de los bibliotecarios y, a su vez, es un factor que les proporciona gran satisfacción, lo cual finalmente se refleja en un buen desempeño laboral. En este sentido, se sugiere que el desempeño laboral exitoso depende de una cultura organizacional sólida y de altos niveles de satisfacción laboral en los trabajadores, por lo que debe ser estudiado como parte integral de ambas variables.

Los análisis de regresión múltiple obtenidos para conocer cuáles factores de la cultura organizacional y de la satisfacción laboral predicen el desempeño laboral para la muestra global mostraron que el primer factor a considerar es la Supervisión-relaciones humanas, seguido por el factor Logro, después por el Acuerdo, continuando con el Aprendizaje organizacional y finalmente con las Oportunidades de promoción. Es decir, para que los bibliotecarios perciban que su desempeño laboral es exitoso es necesario que sientan que su jefe se encarga de ellos y de sus problemas (Togia, Koustelios y Tsigilisb, 2004). También es necesario que sientan que su trabajo 
les proporciona satisfacción y/o éxito. De igual forma, deben percibir que pueden llegar a acuerdos en temas esenciales demostrando que cuentan con la capacidad de resolver sus diferencias. Además, deben sentir que reciben, analizan y utilizan las señales del entorno con el fin de favorecer la innovación, el desarrollo y el conocimiento que poseen. Por último, deben sentir que su trabajo les permite crecer y desarrollarse profesionalmente.

Por otra parte, al realizar el análisis de regresión en hombres y mujeres, de forma separada, el modelo de predicción mostró diferencias entre cada uno de ellos. Para el caso de los hombres, el desempeño laboral está determinado por la Supervisión-relaciones humanas (Togia, Koustelios y Tsigilisb, 2004), seguido por el Estatus social (Berry, 2007-2008; Russell, 1986) y por el Acuerdo. Esto quiere decir que para que el desempeño en el trabajo de los hombres bibliotecarios sea alto es necesario que sientan que su jefe está pendiente de ellos y de sus problemas. También es necesario que perciban que tienen la oportunidad de ser alguien dentro de la comunidad y que sientan que pueden llegar a acuerdos en temas esenciales.

En este análisis se pudo observar una variación en el segundo predictor (Estatus social) que no surgió en el análisis global, es decir, es una variable que únicamente predice el desempeño laboral en los hombres. Este resultado contradice la investigación de Parker y Turner (2002), quienes afirman que no está claro si los mejores puestos de trabajo fomentan un alto desempeño laboral o viceversa. Por el contrario, se encontró que el Estatus social que les proporciona determinado puesto a los hombres bibliotecarios tiende a mejorar su desempeño laboral, por lo que se puede interpretar que para los hombres es fundamental sentirse importantes y ser alguien dentro de la comunidad.

Para el caso de las mujeres, son cuatro las dimensiones que predicen su desempeño en el trabajo. En primer lugar, está la Supervisión-relaciones humanas (Togia, Koustelios y Tsigilisb, 2004), en segundo lugar el Acuerdo, en tercer lugar el Logro (Ferris, Witt y Hochwarter, 2001) y en cuarto lugar la Dirección e integración estratégica. Esto quiere decir que para que las mujeres bibliotecarias perciban que su desempeño laboral es exitoso es necesario que sientan que su jefe se hace cargo de ellas y de sus problemas. Asimismo, deben percibir que pueden llegar a acuerdos en temas esenciales. También deben sentir que su trabajo les proporciona satisfacción y/o éxito y, por último, es necesario que sientan que disponen de un plan estratégico claro que determina el propósito de la biblioteca, mostrando que pueden contribuir al desarrollo de la misma.

En este último caso surgió un nuevo predictor, que no se había observado en el modelo global ni en los hombres: la Dirección e integración estratégica. Estos datos confirman que existen factores en el lugar de trabajo que pueden 
mejorar o potencialmente obstaculizar el desempeño, como los sistemas de dirección y de recompensa, los cuales si son positivos pueden contribuir a la mejora del desempeño laboral (Gerstner y Day, 1997; Podsakoff et al., 2006). En esta investigación se puede observar que la Dirección e integración estratégica surgió únicamente como un predictivo del desempeño laboral en mujeres, lo que implica que para ellas es más importante que sientan que disponen de un plan estratégico claro que determina el propósito de la biblioteca.

Es importante señalar que la profesión de bibliotecario, cuya práctica es ejercida principalmente por mujeres, tal como se puede observar en los resultados obtenidos del presente estudio, se ha visto fuertemente determinada por los roles asignados a hombres y mujeres en una sociedad que ha sido construida y liderada desde un esquema patriarcal, como México (Díaz-Guerrero, 2003).

Lo anterior muestra claramente un papel diferenciado entre hombres y mujeres en cuanto a la percepción de sí mismos. Por ello, se puede argumentar que existen diferencias en el desempeño laboral de los bibliotecarios de las universidades y centros de investigación de la ciudad de Mérida, dependiendo de su sexo. Para los hombres, tener un Estatus social relacionado con su puesto y con poder ser alguien dentro de la comunidad influye en su desempeño laboral, es decir, tienen una perspectiva más individualista de sí mismos. Para las mujeres, es más importante el logro de los propósitos de la biblioteca y que todas las personas puedan contribuir al desarrollo de la misma, es decir, tienen una visión más colectivista de sí mismas y de los demás. En general, México es un país colectivista, aunque existen diferencias entre hombre y mujeres (Hofstede, 1983), como se puede ver en los resultados obtenidos en la presente investigación.

\section{Conclusiones}

A partir de lo anterior se concluye lo siguiente:

1. La cultura organizacional de los bibliotecarios de la ciudad de Mérida está más caracterizada por la misión, entendida como un sentido claro de propósito o dirección, y por el involucramiento, que se concreta en el empoderamiento de la gente, la construcción personal alrededor de los equipos y el desarrollo de la capacidad humana en todos los ámbitos de la biblioteca. Está representada en menor medida por la adaptabilidad y la consistencia. 
2. La satisfacción laboral de los bibliotecarios de la ciudad de Mérida está constituida primordialmente por seis factores: el servicio que prestan a sus usuarios, el sentimiento de logro, la oportunidad de hacer las cosas diferentes de vez en cuando (variedad), las responsabilidades asignadas, el estatus social que les proporciona su labor y la seguridad en su empleo.

3. El desempeño laboral de los bibliotecarios de la ciudad de Mérida está representado principalmente por la actitud amable y atenta para dar servicio a sus usuarios, por la responsabilidad/calidad que les permite realizar de forma adecuada su trabajo, por el cuidado y la protección al medio ambiente mediante prácticas verdes o amigables, por la unión de dos o más personas organizadas que cooperan para lograr un fin común que es la ejecución de un trabajo (trabajo en equipo) y por la buena comunicación para que el trabajo se realice conforme a los requerimientos de la biblioteca.

4. Los resultados obtenidos en el presente estudio reflejan que los bibliotecarios de la ciudad de Mérida muestran una percepción positiva de la cultura organizacional, de la satisfacción laboral y, por consiguiente, del desempeño laboral. Los hallazgos mostraron además que si la percepción de la cultura organizacional es positiva, los bibliotecarios tenderán a sentirse más satisfechos con su trabajo y, por tanto, su desempeño laboral será bueno.

5. El análisis de regresión global demostró que, para predecir el desempeño laboral de los bibliotecarios de las universidades y centros de investigación de la ciudad de Mérida, los factores a considerar son la supervisión-relaciones humanas, seguido por el factor logro, después por el acuerdo, continuando con el aprendizaje organizacional y finalmente con las oportunidades de promoción.

6. El modelo de regresión por sexo arrojó diferencias entre hombres y mujeres. Para los hombres, el poder tener un estatus social influye en su desempeño laboral. Para las mujeres, el tener una buena dirección e integración estratégica influye en mayor medida en su desempeño laboral.

Finalmente, se puede decir que estudiar las variables cultura organizacional, satisfacción laboral y desempeño laboral en el contexto bibliotecológico fue de gran utilidad ya que permitió abordar un campo de estudio poco trabajado, así como también conocer cómo se manifiestan estas variables en las bibliotecas yucatecas las cuales, en su mayoría, tuvieron resultados positivos. A partir de estos hallazgos se hace necesario continuar con el estudio 
del impacto de estas variables en las bibliotecas, tanto desde la perspectiva de otros bibliotecarios como desde la de jefes y usuarios; por ello, se sugiere seguirlas explorando en futuras investigaciones así como introducir nuevas variables que pudieran ayudar a precisar aún más la medición y predicción del desempeño laboral.

\section{REFERENCIAS}

Berry, J. N. 2007-2008. “Great work, genuine problems”. Library Journal 132 (16): 26-29. Bonavia, T., V. J. Prado y D. Barberá. 2009. "Adaptación al castellano y estructura factorial del Denison Organizational Culture Survey”. Psicothema 21 (4): 633-638.

Bravo, M. J., J. M. Peiró e I. Rodríguez. 1996. "Satisfacción laboral”, en Tratado de psicología del trabajo, editado por J. Peiró y F. Prieto, 343-394. México: Síntesis.

Calleja, N. 1988. "El desempeño y la satisfacción laboral del bibliotecario: Construcción de escalas de medición”. Investigación Bibliotecológica 2 (4): 11-24.

Chiavenato, I. 2011. Administración de Recursos Humanos: El capital bumano de las organizaciones, 9a ed. México: McGraw Hill.

Cronbach, L. J. 1951. "Coefficient alpha and the internal structure of tests". Psychometrika 16 (3): 297-334.

Denison, D. R. 1991. Cultura corporativa y productividad organizacional. Traducido por J. Villamizar. Bogotá: Legis Fondo Editorial.

Denison, D. R. y W. Neal. 1994. Denison Organizational Culture Survey. Ann Arbor, Michigan: Aviat.

Department of Psychology, University of Minnesota. 2017. "Vocational Psychology Research”. http://vpr.psych.umn.edu/instruments/msq-minnesota-satisfaction-questionnaire.

Díaz-Guerrero, R. 2003. Psicología del mexicano, 6a. reimp. México: Trillas.

Diskienè, D. y V. Goštautas. 2010. "Relationship between individual and organizational values and employees job satisfaction”. Current Issues of Business and Law 5 (2): 295-319.

Ferris, G. R., L. A. Witt y W. A. Hochwarter. 2001. "Interaction of social skill and general mental ability on job performance and salary". Journal of Applied Psychology 86: 1075-1082.

Flynn, F. y J. Chatman. 2001. "Strong cultures and innovation: Oxymoron or opportunity?", en International handbook of organizational culture and climate, editado por C. L. Cooper, 263-287. Nueva York: John Wiley \& Sons.

Gerstner, C. R. y D. V. Day. 1997. "Meta-analytic review of leader-member exchange theory: Correlates and construct issues". Journal of Applied Psychology 82: 827-844.

Gibson, J. L., J. H. Ivancevich, J. H. Donelly y J. Vázquez. 1996. Las organizaciones: comportamiento, estructura y procesos, 8a ed. Cd. de México: McGraw Hill.

Griffin, R. W. y T. S. Bateman. 1986. "Job satisfaction and organizational commitment”, en International and Organizational Psychology, editado por C. L. Cooper e I. Robertson. Chischester, Inglaterra: Wiley \& Sons. 
Griffin, M. A., A. Neal y M. Neale. 2000. “The contribution of task performance and contextual performance to effectiveness: Investigating the role of situational constraints". Applied Psychology: An International Review 49: 479-497.

Hernández Pacheco, F. 2012. "Cultura organizacional”, en Gestión y desarrollo de recursos bumanos en bibliotecas, editado por José López Yepes, Hugo Figueroa Alcántara y Juan José Calva González, 227-255. México: Escuela Nacional de Biblioteconomía y Archivonomía: Universidad Complutense de Madrid.

Hinojosa, C. 2010. "Clima organizacional y satisfacción laboral de profesores del Colegio Sagrados Corazones Padres Franceses”. Tesis doctoral, Universidad de Playa Ancha, Programa de Doctorado en Gestión y Políticas Educativas.

Hobson, C. J., R. F. Moran y A. L. Stevens. 1987. "Circulation/ reserve desk personnel effectiveness”. The Journal of Academic Librarianship 13 (2): 93-98.

Hofstede, G. 1983. "The cultural relativity of organizational practices and theories”. Journal of International Business Studies 14 (2): 75-89.

Ivancevich, J. M., R. Konopaske y M. T. Matteson. 2006. Comportamiento organizacional. México: McGraw Hill Interamericana.

Kusluvan, Z. y K. Karamustafa. 2003. "Managing employee attitudes and behaviors in tourism and hospitality organizations", en Organizational cultures and its impacts on employee attitudes and behaviors in tourism and hospitality industry, editado por Z. Kusluvan, 453-485. Nueva York: Nova Science Publishers.

Lewis, M. 1980. "Management by objectives: Review, application and relationships with job satisfaction and performance". The Journal of Academic Librarianship 5 (6): 329-334.

Lok, P. y J. Crawford. 1999. “The relationship between commitment and organizational culture, subculture, leadership style and job satisfaction in organizational change and development". Leadership \& Organizational Development 20 (7):365-376.

Lozano, R. 2009. "Gestión del cambio y cultura organizacional en la biblioteca pública”. Educación y biblioteca: Revista mensual de documentación y recursos didácticos 21 (170): 101-106.

Lukić, T., V. Džamić, G. Knežević, S. Alčaković y V. Bošković. 2014. “The influence of organizational culture on business creativity, innovation and satisfaction". Management, 57: 49-57.

Lund, B. D. 2003. "Organizational culture and job satisfaction”. Journal of Business EIndustrial Marketing 18 (30): 219-236.

Martínez, M. E. 2010. "Relaciones entre cultura y desempeño organizacional en una muestra de empresas colombianas: Reflexiones sobre la utilización del modelo de Denison”. Cuadernos de Administración 23 (40): 163-190.

Morgan, C. 2014. "Craft and librarianship: A reconsideration of the sources of librarian job satisfaction". Journal of Library Administration, 54: 637-658.

Ouchi, W. G. y A. L. Wilkins. 1985. “Organizational culture”. Annual Review of Sociology, 11: 457-483.

Oyewole, G. O. y S. O. Popoola. 2013. "Effects of psycho-social factors on job performance of library personnel in federal colleges of education in Nigeria”. Library Philosophy and Practice (e-journal), 872. 
Parker, S. K. y N. Turner. 2002. "Work design and individual work performance: Research findings and an agenda for future inquiry", en The Psychological Management of Individual Performance: A Handbook in the Psychology of the Management of Organizations, editado por Sabine Sonnentag, 69-93. Chichester: Erlbaum.

Peña, M., A. Olloqui y A. Aguilar. 2013. "Relación de factores en la satisfacción laboral de los trabajadores de una pequeña empresa de la industria metal-mecánica”. Revista Internacional de Administración y Finanzas 6 (3): 115-128.

Peng, Y. P. 2014. "Job satisfaction and job performance of university librarians: A disaggregated examination”. Library and Information Science Research, 36:74- 82.

Podsakoff, P. M., W. H. Bommer, N. P. Podsakoff y S. B. MacKenzie. 2006. "Relationships between leader reward and punishment behavior and subordinate attitudes, perceptions and behaviors: A meta-analytic review of existing and new research". Organizational Behavior and Human Decision Processes, 99: 113-142.

Quijano Solís, Á. 2007. "El factor humano y el desarrollo organizacional en bibliotecas", en Ambiente laboral: Estrategias para el trabajo efectivo en bibliotecas, editado por Jesús Lau, 33-47. México: Alfagrama.

Robbins, S. y T. Judge. 2013. Comportamiento organizativo. México: Pearson.

Russell, N. J. 1986. The job satisfaction on non-professional library staff. Australia: Libraries Australia.

Schlosser, M. 2010. "Fostering organizational change through a grassroots planning process". College and Research Libraries 72 (2): 152-165.

Seoko, S. 1978. "A comparative study of job satisfaction: Catalogers and reference librarians in university libraries”. The Journal of Academic Librarianship 4 (3): 139-143.

Silverthorne, C. 2004. "The impact of organizational culture and person-organization fit on organizational commitment and job satisfaction in Taiwan”. Leadership \& Organization Development Journal, 25: 592-599.

Togia, A., A. Koustelios y N. Tsigilisb. 2004. "Job satisfaction among Greek academic librarians". Library and Information Science Research, 26: 373-383.

Vargas, S. 2012. "Diseño de una metodología para contribuir al diagnóstico de la cultura organizacional en bibliotecas académicas”. Tesis de Maestría, El Colegio de México, Programa de Maestría en Bibliotecología.

Viswesvaran, C. y D. Ones. 2000. "Perspectives on models of job performance". International Journal of Selection and Assessment 8 (4): 216-226.

Weiss, D. J., R. V. Dawis, G. W. England y L. H. Lofquist. 1967. Manual for the Minnesota Satisfaction Questionnaire, vol. 22. Minnesota Studies in Vocational Rehabilitation.

Zaragoza, A. 2012. Bibliotecas universitarias: Elementos estratégicos para la transformación de su cultura organizacional. México: Adrián Zaragoza Tapia. 


\section{Apéndice A}

Denison Organizational Culture Survey

Pregúntese a sí mismo: ¿Qué tan satisfecho estoy con este aspecto de mi trabajo?

1. NO ESTOY SATISFECHO (este aspecto de mi trabajo está muy lejos de lo que desearía).

2. ESTOY POCO SATISFECHO (este aspecto de mi trabajo no es exactamente lo que desearía).

3. ESTOY SATISFECHO (este aspecto de mi trabajo es lo que yo desearía).

4. ESTOY MUY SATISFECHO (este aspecto de mi trabajo es mejor de lo que yo esperaba).

5. ESTOY EXTREMADAMENTE SATISFECHO (este aspecto de mi trabajo está mucho mejor de lo que yo esperaría).

\begin{tabular}{|c|c|c|c|c|c|}
\hline En mi puesto actual de trabajo ocurre lo siguiente... & & & $c$ & & \\
\hline $\begin{array}{l}\text { 1. La mayoría de los miembros de este grupo están muy comprometidos con } \\
\text { su trabajo. }\end{array}$ & 1 & 2 & 3 & 4 & 5 \\
\hline $\begin{array}{l}\text { 2. Las decisiones con frecuencia se toman en el nivel que dispone de la mejor } \\
\text { información. }\end{array}$ & 1 & 2 & 3 & 4 & 5 \\
\hline $\begin{array}{l}\text { 3. La información se comparte ampliamente y se puede conseguir cuando se } \\
\text { necesita. }\end{array}$ & 1 & 2 & 3 & 4 & 5 \\
\hline 4. Cada miembro cree que puede tener un impacto positivo en el grupo. & 1 & 2 & 3 & 4 & 5 \\
\hline $\begin{array}{l}\text { 5. La planificación de nuestro trabajo es continua e implica a todo el mundo } \\
\text { en algún grado. }\end{array}$ & 1 & 2 & 3 & 4 & 5 \\
\hline $\begin{array}{l}\text { 6. Se fomenta activamente la cooperación entre los diferentes grupos de esta } \\
\text { organización. }\end{array}$ & 1 & 2 & 3 & 4 & 5 \\
\hline 7. Trabajar en este grupo es como formar parte de un equipo. & 1 & 2 & 3 & 4 & 5 \\
\hline $\begin{array}{l}\text { 8. Acostumbramos a realizar las tareas en equipo, en vez de descargar el } \\
\text { peso en la dirección. }\end{array}$ & 1 & 2 & 3 & 4 & 5 \\
\hline $\begin{array}{l}\text { 9. Los grupos y no los individuos son los principales pilares de esta organi- } \\
\text { zación. }\end{array}$ & 1 & 2 & 3 & 4 & 5 \\
\hline $\begin{array}{l}\text { 10. El trabajo se organiza de modo que cada persona entiende la relación } \\
\text { entre su trabajo y los objetivos de la organización. }\end{array}$ & 1 & 2 & 3 & 4 & 5 \\
\hline $\begin{array}{l}\text { 11. La autoridad se delega de modo que las personas puedan actuar por sí } \\
\text { mismas. }\end{array}$ & 1 & 2 & 3 & 4 & 5 \\
\hline $\begin{array}{l}\text { 12. Las capacidades del «banquillo» (los futuros líderes en el grupo) se } \\
\text { mejoran constantemente. }\end{array}$ & 1 & 2 & 3 & 4 & 5 \\
\hline
\end{tabular}




\begin{tabular}{|c|c|c|c|c|c|}
\hline $\begin{array}{l}\text { 13. Este grupo invierte continuamente en el desarrollo de las capacidades de } \\
\text { sus miembros. }\end{array}$ & 1 & 2 & 3 & 4 & 5 \\
\hline $\begin{array}{l}\text { 14. La capacidad de las personas es vista como una fuente importante de } \\
\text { ventaja competitiva. }\end{array}$ & 1 & 2 & 3 & 4 & 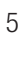 \\
\hline 15. Los líderes y directores practican lo que pregonan. & 1 & 2 & 3 & 4 & 5 \\
\hline $\begin{array}{l}\text { 16. Existe un estilo de dirección característico con un conjunto de prácticas } \\
\text { distintivas. }\end{array}$ & 1 & 2 & 3 & 4 & 5 \\
\hline $\begin{array}{l}\text { 17. Existe un conjunto de valores claro y consistente que rige la forma en que } \\
\text { nos conducimos. }\end{array}$ & 1 & 2 & 3 & 4 & 5 \\
\hline 18. Ignorar los valores esenciales de este grupo te ocasionará problemas. & 1 & 2 & 3 & 4 & 5 \\
\hline $\begin{array}{l}\text { 19. Existe un código ético que guía nuestro comportamiento y nos ayuda a } \\
\text { distinguir lo correcto. }\end{array}$ & 1 & 2 & 3 & 4 & 5 \\
\hline $\begin{array}{l}\text { 20. Cuando existen desacuerdos, trabajamos intensamente para encontrar } \\
\text { soluciones donde todos ganen. }\end{array}$ & 1 & 2 & 3 & 4 & 5 \\
\hline 21. Este grupo tiene una cultura «fuerte». & 1 & 2 & 3 & 4 & 5 \\
\hline 22. Nos resulta fácil lograr el consenso, aún en temas difíciles. & 1 & 2 & 3 & 4 & 5 \\
\hline 23. A menudo tenemos dificultades para alcanzar acuerdos en temas clave. & 1 & 2 & 3 & 4 & 5 \\
\hline $\begin{array}{l}\text { 24. Existe un claro acuerdo acerca de la forma correcta e incorrecta de hacer } \\
\text { las cosas. }\end{array}$ & 1 & 2 & 3 & 4 & 5 \\
\hline 25. Nuestra manera de trabajar es consistente y predecible. & 1 & 2 & 3 & 4 & 5 \\
\hline $\begin{array}{l}\text { 26. Las personas de diferentes grupos de esta organización tienen una } \\
\text { perspectiva común. }\end{array}$ & 1 & 2 & 3 & 4 & 5 \\
\hline $\begin{array}{l}\text { 27. Es sencillo coordinar proyectos entre los diferentes grupos de esta } \\
\text { organización. }\end{array}$ & 1 & 2 & 3 & 4 & 5 \\
\hline $\begin{array}{l}\text { 28. Existe una buena alineación de objetivos entre los diferentes niveles } \\
\text { jerárquicos. }\end{array}$ & 1 & 2 & 3 & 4 & 5 \\
\hline 29. La forma que tenemos de hacer las cosas es flexible y fácil de cambiar. & 1 & 2 & 3 & 4 & 5 \\
\hline 30. Respondemos bien a los cambios del entorno. & 1 & 2 & 3 & 4 & 5 \\
\hline 31. Adoptamos de continuo nuevas y mejores formas de hacer las cosas. & 1 & 2 & 3 & 4 & 5 \\
\hline 32. Los intentos de realizar cambios suelen encontrar resistencias. & 1 & 2 & 3 & 4 & 5 \\
\hline $\begin{array}{l}\text { 33. Los diferentes grupos de esta organización cooperan a menudo para } \\
\text { introducir cambios. }\end{array}$ & 1 & 2 & 3 & 4 & 5 \\
\hline $\begin{array}{l}\text { 34. Los comentarios y recomendaciones de nuestros usuarios conducen a } \\
\text { menudo a introducir cambios. }\end{array}$ & 1 & 2 & 3 & 4 & 5 \\
\hline 35. La información sobre nuestros usuarios influye en nuestras decisiones. & 1 & 2 & 3 & 4 & 5 \\
\hline $\begin{array}{l}\text { 36. Todos tenemos una comprensión profunda de los deseos y necesidades } \\
\text { de nuestro entorno. }\end{array}$ & 1 & 2 & 3 & 4 & 5 \\
\hline 37. Nuestras decisiones ignoran con frecuencia los intereses de los usuarios. & 1 & 2 & 3 & 4 & 5 \\
\hline 38. Fomentamos el contacto directo de nuestra gente con los usuarios. & 1 & 2 & 3 & 4 & 5 \\
\hline 39. Consideramos el fracaso como una oportunidad para aprender y mejorar. & 1 & 2 & 3 & 4 & 5 \\
\hline
\end{tabular}




\begin{tabular}{|c|c|c|c|c|c|}
\hline 40. Tomar riesgos e innovar son fomentados y recompensados. & 1 & 2 & 3 & 4 & 5 \\
\hline 41. Muchas ideas «se pierden por el camino». & 1 & 2 & 3 & 4 & 5 \\
\hline 42. El aprendizaje es un objetivo importante en nuestro trabajo cotidiano. & 1 & 2 & 3 & 4 & 5 \\
\hline $\begin{array}{l}\text { 43. Nos aseguramos que «la mano derecha sepa lo que está haciendo la } \\
\text { izquierda». }\end{array}$ & 1 & 2 & 3 & 4 & 5 \\
\hline 44. Esta organización tiene un proyecto y una orientación a largo plazo. & 1 & 2 & 3 & 4 & 5 \\
\hline 45. Nuestra estrategia sirve de ejemplo a otras organizaciones. & 1 & 2 & 3 & 4 & 5 \\
\hline $\begin{array}{l}\text { 46. Esta organización tiene una misión clara que le otorga sentido y rumbo a } \\
\text { nuestro trabajo. }\end{array}$ & 1 & 2 & 3 & 4 & 5 \\
\hline 47. Esta organización tiene una clara estrategia de cara al futuro. & 1 & 2 & 3 & 4 & 5 \\
\hline 48. Existe un amplio acuerdo sobre las metas a conseguir. & 1 & 2 & 3 & 4 & 5 \\
\hline 49. Los líderes y directores fijan metas ambiciosas pero realistas. & 1 & 2 & 3 & 4 & 5 \\
\hline 50. La dirección nos conduce hacia los objetivos que tratamos de alcanzar. & 1 & 2 & 3 & 4 & 5 \\
\hline 51. Comparamos continuamente nuestro progreso con los objetivos fijados. & 1 & 2 & 3 & 4 & 5 \\
\hline $\begin{array}{l}\text { 52. Las personas de esta organización comprenden lo que hay que hacer } \\
\text { para tener éxito a largo plazo. }\end{array}$ & 1 & 2 & 3 & 4 & 5 \\
\hline $\begin{array}{l}\text { 53. Tenemos una visión compartida de cómo será esta organización en el } \\
\text { futuro. }\end{array}$ & 1 & 2 & 3 & 4 & 5 \\
\hline 54. Los líderes y directores tienen una perspectiva a largo plazo. & 1 & 2 & 3 & 4 & 5 \\
\hline 55. Nuestra visión genera entusiasmo y motivación entre nosotros. & 1 & 2 & 3 & 4 & 5 \\
\hline $\begin{array}{l}\text { 56. Podemos satisfacer las demandas a corto plazo sin comprometer nuestra } \\
\text { visión a largo plazo. }\end{array}$ & 1 & 2 & 3 & 4 & 5 \\
\hline
\end{tabular}

\section{Apéndice B}

Cuestionario de Satisfacción Laboral de Minnesota

Pregúntese a sí mismo: ¿Qué tan satisfecho estoy con este aspecto de mi trabajo?

1. NO ESTOY SATISFECHO (este aspecto de mi trabajo está muy lejos de lo que desearía).

2. ESTOY POCO SATISFECHO (este aspecto de mi trabajo no es exactamente lo que desearía).

3. ESTOY SATISFECHO (este aspecto de mi trabajo es lo que yo desearía).

4. ESTOY MUY SATISFECHO (este aspecto de mi trabajo es mejor de lo que yo esperaba).

5. ESTOY EXTREMADAMENTE SATISFECHO (este aspecto de mi trabajo está mucho mejor de lo que yo esperaría). 


\begin{tabular}{|c|c|c|c|c|c|}
\hline \multirow{2}{*}{$\begin{array}{l}\text { En mi puesto actual de trabajo siento lo siguiente acerca de... } \\
\text { 1. La oportunidad de servir a otros. }\end{array}$} & \multicolumn{5}{|c|}{$\begin{array}{l}\text { Marque con un } \\
\text { círculo un número } \\
\text { para cada } \\
\text { afirmación }\end{array}$} \\
\hline & 1 & 2 & 3 & 4 & 5 \\
\hline 2. La variedad de mi trabajo. & 1 & 2 & 3 & 4 & 5 \\
\hline 3. La posición social que el trabajo me da en la comunidad. & 1 & 2 & 3 & 4 & 5 \\
\hline 4. Las políticas y prácticas hacia los empleados en esta biblioteca. & 1 & 2 & 3 & 4 & 5 \\
\hline 5. La forma como mi supervisor y yo nos entendemos. & 1 & 2 & 3 & 4 & 5 \\
\hline 6. La seguridad de mi trabajo. & 1 & 2 & 3 & 4 & 5 \\
\hline 7. La cantidad de pago por el trabajo que hago. & 1 & 2 & 3 & 4 & 5 \\
\hline 8. Las condiciones de trabajo como: temperatura, luz y ventilación. & 1 & 2 & 3 & 4 & 5 \\
\hline 9. Las oportunidades de mejorar en este trabajo. & 1 & 2 & 3 & 4 & 5 \\
\hline 10. El espíritu de cooperación entre mis colegas. & 1 & 2 & 3 & 4 & 5 \\
\hline 11. La oportunidad de ser responsable de planear mi trabajo. & 1 & 2 & 3 & 4 & 5 \\
\hline 12. La forma como se me distingue cuando hago un buen trabajo. & 1 & 2 & 3 & 4 & 5 \\
\hline 13. Ser capaz de ver los resultados del trabajo que hago. & 1 & 2 & 3 & 4 & 5 \\
\hline 14. La oportunidad de estar al servicio de otra gente. & 1 & 2 & 3 & 4 & 5 \\
\hline 15. La oportunidad de hacer cosas diferentes de vez en cuando. & 1 & 2 & 3 & 4 & 5 \\
\hline 16. La oportunidad de ser "alguien" en la comunidad. & 1 & 2 & 3 & 4 & 5 \\
\hline 17. Las políticas de la biblioteca y la manera como se administran. & 1 & 2 & 3 & 4 & 5 \\
\hline 18. La forma como mi jefe maneja a sus empleados. & 1 & 2 & 3 & 4 & 5 \\
\hline 19. La manera como mi trabajo me provee de un futuro más seguro. & 1 & 2 & 3 & 4 & 5 \\
\hline 20. La oportunidad de hacer tanto dinero como mis amigos. & 1 & 2 & 3 & 4 & 5 \\
\hline 21. El medio ambiente del lugar donde trabajo. & 1 & 2 & 3 & 4 & 5 \\
\hline 22. La oportunidad de avanzar en este trabajo. & 1 & 2 & 3 & 4 & 5 \\
\hline 23. La oportunidad de hacer amigos cercanos entre mis compañeros. & 1 & 2 & 3 & 4 & 5 \\
\hline 24. La capacidad de tomar decisiones por mí mismo. & 1 & 2 & 3 & 4 & 5 \\
\hline 25. La manera como yo obtengo crédito completo por mi trabajo. & 1 & 2 & 3 & 4 & 5 \\
\hline 26. Ser capaz de estar orgulloso de un trabajo bien hecho. & 1 & 2 & 3 & 4 & 5 \\
\hline 27. La oportunidad de ayudar a otra gente. & 1 & 2 & 3 & 4 & 5 \\
\hline 28. La oportunidad de estar solo en mi trabajo. & 1 & 2 & 3 & 4 & 5 \\
\hline 29. La oportunidad de relacionarme con gente importante. & 1 & 2 & 3 & 4 & 5 \\
\hline 30. La manera como se informan las políticas de la biblioteca. & 1 & 2 & 3 & 4 & 5 \\
\hline 31. El apoyo administrativo que mi jefe ofrece a sus empleados. & 1 & 2 & 3 & 4 & 5 \\
\hline 32. La manera como mi trabajo me otorga seguridad en el empleo. & 1 & 2 & 3 & 4 & 5 \\
\hline 33. Como mi salario se compara al de otros en otras bibliotecas. & 1 & 2 & 3 & 4 & 5 \\
\hline
\end{tabular}




\begin{tabular}{|c|c|c|c|c|c|}
\hline 34. Lo placentero de las condiciones de mi trabajo. & 1 & 2 & 3 & 4 & 5 \\
\hline 35. Las formas como las promociones se dan en este trabajo. & 1 & 2 & 3 & 4 & 5 \\
\hline 36. La camaradería de mis colegas. & 1 & 2 & 3 & 4 & 5 \\
\hline 37. La oportunidad de ser responsable en el trabajo de otros. & 1 & 2 & 3 & 4 & 5 \\
\hline 38. El reconocimiento que tengo por el trabajo que hago. & 1 & 2 & 3 & 4 & 5 \\
\hline 39. La oportunidad de hacer algo que valga la pena. & 1 & 2 & 3 & 4 & 5 \\
\hline 40. La oportunidad de hacer algo por mi prójimo. & 1 & 2 & 3 & 4 & 5 \\
\hline 41. La oportunidad de hacer algo diferente todos los días. & 1 & 2 & 3 & 4 & 5 \\
\hline 42. La oportunidad de ser importante ante los demás. & 1 & 2 & 3 & 4 & 5 \\
\hline 43. La forma como las políticas de la biblioteca se ponen en práctica. & 1 & 2 & 3 & 4 & 5 \\
\hline 44. La forma como mi jefe toma las quejas de sus empleados. & 1 & 2 & 3 & 4 & 5 \\
\hline 45. Lo estable que es mi trabajo. & 1 & 2 & 3 & 4 & 5 \\
\hline 46. Mi paga y la cantidad de trabajo que hago. & 1 & 2 & 3 & 4 & 5 \\
\hline 47. Las condiciones físicas de mi trabajo. & 1 & 2 & 3 & 4 & 5 \\
\hline 48. Las oportunidades de promoción en este trabajo. & 1 & 2 & 3 & 4 & 5 \\
\hline 49. La forma en que mis colegas son amigables. & 1 & 2 & 3 & 4 & 5 \\
\hline 50. La libertad para utilizar mis propios juicios. & 1 & 2 & 3 & 4 & 5 \\
\hline 51. La manera como se me dice que hago bien mi trabajo. & 1 & 2 & 3 & 4 & 5 \\
\hline 52. La oportunidad de dar lo mejor de mí todo el tiempo. & 1 & 2 & 3 & 4 & 5 \\
\hline 53. La oportunidad de dar un pequeño servicio a otras personas. & 1 & 2 & 3 & 4 & 5 \\
\hline 54. La oportunidad de hacer muchas cosas diferentes en el trabajo. & 1 & 2 & 3 & 4 & 5 \\
\hline 55. La oportunidad de tener un lugar definido en la comunidad. & 1 & 2 & 3 & 4 & 5 \\
\hline 56. La forma como la institución trata a sus empleados. & 1 & 2 & 3 & 4 & 5 \\
\hline 57. Las relaciones personales entre mi jefe y sus empleados. & 1 & 2 & 3 & 4 & 5 \\
\hline 58. La forma como los despidos y los cambios se evitan en mi trabajo. & 1 & 2 & 3 & 4 & 5 \\
\hline 59. Como mi salario se compara con el de otros bibliotecarios. & 1 & 2 & 3 & 4 & 5 \\
\hline 60. Las condiciones de mi trabajo. & 1 & 2 & 3 & 4 & 5 \\
\hline 61. Mis oportunidades para avanzar. & 1 & 2 & 3 & 4 & 5 \\
\hline 62. La forma como mis colegas se llevan entre sí. & 1 & 2 & 3 & 4 & 5 \\
\hline 63. La responsabilidad en mi trabajo. & 1 & 2 & 3 & 4 & 5 \\
\hline 64. El reconocimiento que obtengo por hacer un buen trabajo. & 1 & 2 & 3 & 4 & 5 \\
\hline 65. Los logros que obtengo por hacer un buen trabajo. & 1 & 2 & 3 & 4 & 5 \\
\hline
\end{tabular}




\section{Apéndice C}

Escala de Desempeño Laboral para Bibliotecarios

Pregúntese a sí mismo: ¿Qué tan satisfecho estoy con este aspecto de mi trabajo?

1. NO ESTOY SATISFECHO (este aspecto de mi trabajo está muy lejos de lo que desearía).

2. ESTOY POCO SATISFECHO (este aspecto de mi trabajo no es exactamente lo que desearía).

3. ESTOY SATISFECHO (este aspecto de mi trabajo es lo que yo desearía).

4. ESTOY MUY SATISFECHO (este aspecto de mi trabajo es mejor de lo que yo esperaba).

5. ESTOY EXTREMADAMENTE SATISFECHO (este aspecto de mi trabajo está mucho mejor de lo que yo esperaría).

\begin{tabular}{|c|c|c|c|c|c|}
\hline En mi puesto actual de trabajo siento lo siguiente acerca de... & \multicolumn{5}{|c|}{$\begin{array}{c}\text { Marque con un } \\
\text { círculo un número } \\
\text { para cada } \\
\text { afirmación }\end{array}$} \\
\hline 1. Demuestro amabilidad al brindar servicio al usuario. & 1 & 2 & 3 & 4 & 5 \\
\hline 2. Soy atento con los usuarios. & 1 & 2 & 3 & 4 & 5 \\
\hline $\begin{array}{l}\text { 3. Tengo disposición para resolver las solicitudes de información de los } \\
\text { usuarios. }\end{array}$ & 1 & 2 & 3 & 4 & 5 \\
\hline 4. Resuelvo con rapidez una solicitud de información. & 1 & 2 & 3 & 4 & 5 \\
\hline 5. Logro conseguir la información que requiere el usuario. & 1 & 2 & 3 & 4 & 5 \\
\hline $\begin{array}{l}\text { 6. Ofrezco al usuario información complementaria que satisfaga mejor su } \\
\text { requerimiento de información. }\end{array}$ & 1 & 2 & 3 & 4 & 5 \\
\hline 7. Demuestro mucho interés por mi trabajo. & 1 & 2 & 3 & 4 & 5 \\
\hline 8. Demuestro una gran vocación al realizar mi trabajo. & 1 & 2 & 3 & 4 & 5 \\
\hline 9. Tengo ritmo sostenido y rápido en mi trabajo. & 1 & 2 & 3 & 4 & 5 \\
\hline 10. Me gusta que mi trabajo salga a la perfección. & 1 & 2 & 3 & 4 & 5 \\
\hline $\begin{array}{l}\text { 11. Recibo "en forma oportuna" de mi jefe, la información que requiero para } \\
\text { realizar mi trabajo. }\end{array}$ & 1 & 2 & 3 & 4 & 5 \\
\hline 12. Existen oportunidades para dar a conocer mis ideas con mis compañeros. & 1 & 2 & 3 & 4 & 5 \\
\hline $\begin{array}{l}\text { 13. Existen oportunidades para compartir las mejores prácticas de conoci- } \\
\text { mientos de mi trabajo con mi jefe. }\end{array}$ & 1 & 2 & 3 & 4 & 5 \\
\hline $\begin{array}{l}\text { 14. Existe un sistema de comunicación de doble vía (jefe-colaborador, } \\
\text { colaborador-jefe). }\end{array}$ & 1 & 2 & 3 & 4 & 5 \\
\hline 15. Realizo mis funciones y actividades en tiempo y forma. & 1 & 2 & 3 & 4 & 5 \\
\hline $\begin{array}{l}\text { 16. Es mi responsabilidad entregar los productos de mi trabajo cumpliendo } \\
\text { con las especificaciones solicitadas. }\end{array}$ & 1 & 2 & 3 & 4 & 5 \\
\hline
\end{tabular}




\begin{tabular}{|l|c|c|c|c|c|}
\hline $\begin{array}{l}\text { 17. Es mi responsabilidad entregar los productos de mi trabajo en el formato } \\
\text { adecuado y con la información completa. }\end{array}$ & 2 & 3 & 4 & 5 \\
\hline $\begin{array}{l}\text { 18. Me considero una persona responsable en la entrega de los productos de } \\
\text { mi trabajo. }\end{array}$ & 1 & 2 & 3 & 4 & 5 \\
\hline 19. Cuando se requiere hacer un trabajo en grupo, me muestro cooperativo. & 1 & 2 & 3 & 4 & 5 \\
\hline $\begin{array}{l}\text { 20. En actividades conjuntas, colaboro con mis compañeros y realizo la parte } \\
\text { del trabajo que me corresponde. }\end{array}$ & 1 & 2 & 3 & 4 & 5 \\
\hline 21. Me siento en todo momento apoyado por el grupo de trabajo. & 1 & 2 & 3 & 4 & 5 \\
\hline 22. En la biblioteca se fomenta y desarrolla el trabajo en equipo. & 1 & 2 & 3 & 4 & 5 \\
\hline $\begin{array}{l}\text { 23. El grupo se mantiene unido para alcanzar una meta común después de } \\
\text { que se ha acordado. }\end{array}$ & 1 & 2 & 3 & 4 & 5 \\
\hline 24. Tengo los conocimientos para realizar las tareas propias de mi puesto. & 1 & 2 & 3 & 4 & 5 \\
\hline 25. Conozco las normas y procedimientos del trabajo que realizo. & 1 & 2 & 3 & 4 & 5 \\
\hline 26. Comprendo las tareas y técnicas del trabajo que realizo. & 1 & 2 & 3 & 4 & 5 \\
\hline $\begin{array}{l}\text { 27. Poseo las habilidades específicas que se requieren para realizar todas las } \\
\text { facetas de mi trabajo. }\end{array}$ & 1 & 2 & 3 & 4 & 5 \\
\hline 28. Apago las lámparas de luz que no se utilizan. & 1 & 2 & 3 & 4 & 5 \\
\hline 29. Existe en la biblioteca una conciencia de ahorro de agua. & 1 & 2 & 3 & 4 & 5 \\
\hline 30. Reciclo y reutilizo el papel y cartón usado. & 2 & 3 & 4 & 5 \\
\hline 31. Fomento la protección y cuidado al medio ambiente en mi trabajo. & & 1 & 5 \\
\hline
\end{tabular}

\section{Para citar este texto:}

Vargas Echeverría, Shilia Lisset y Mirta Margarita Flores Galaz. 2019. "Cultura organizacional y satisfacción laboral como predictores del desempeño laboral en bibliotecarios”. Investigación Bibliotecológica: archivonomia, bibliotecología e información 33 (79): 149-176. http://dx.doi.org/10.22201/iibi.24488321xe.2019.79.57913 